\title{
Development of Rutting Damage Ratios of Heavy Vehicles Operating in the Northern Part of Peninsular Malaysia
}

\author{
Osama M. Yassenn ${ }^{1}$, Intan R. Endut ${ }^{2}$, Mohamed A. Hafez ${ }^{3} \&$ Siti Z. Ishak $^{1}$ \\ ${ }^{1}$ Malaysia Institute of Transport, Universiti Teknologi MARA, Shah Alam, Selangor, Malaysia \\ ${ }^{2}$ Faculty of Civil Engineering, Universiti Teknologi MARA, Shah Alam, Selangor, Malaysia \\ ${ }^{3}$ Department of Civil Engineering, Universiti Tenaga Nasional, Kajang, Selangor, Malaysia \\ Correspondence: Osama Mahmoud Yassenn, Malaysia Institute of Transport, Universiti Teknologi MARA, \\ 40450, Shah Alam, Selangor, Malaysia. Tel: 60-193-692-471. E-mail: eng.osama.alhusyni@gmail.com
}

Received: December 30, 2014

Accepted: February 17, 2015 Online Published: August 30, 2015

doi:10.5539/mas.v9n9p344

URL: http://dx.doi.org/10.5539/mas.v9n9p344

\begin{abstract}
Heavy vehicles loaded beyond load limits are found to form a considerable percentage of heavy vehicles traffic in the Northern Part of Malaysian Peninsula. This study uses the actual weights of heavy vehicles to develop rutting damage ratios for each heavy vehicle type to be used in flexible pavement and overlay design. Traffic volume and heavy vehicles weights were collected by five survey stations spread along the northern part of Malaysian peninsula, namely: Alor Setar, Gurun, Bertam, Bukit Merah, and Taiping. Via the analysis, rutting damage ratios were developed for each heavy vehicle classes and an average rutting damage ratio was developed to represent all types of heavy vehicles running in the northern part of Malaysian peninsula.
\end{abstract}

Keywords: rutting damage, rutting damage ratio, flexible pavement, heavy vehicles, Malaysia

\section{Introduction}

The economic development of Malaysia depends largely on its transportation systems and transportation infrastructures. For the purpose of maintaining this rapid development, it is important to keep these infrastructures at the highest possible quality. The most important transportation infrastructure in Malaysia is the road network. However, this infrastructure is encountering several problems, one of the most important problems it is facing nowadays is the overloading of heavy vehicles. Several published studies, which investigated the weight of heavy vehicles in Malaysia found that the overloaded heavy vehicles are forming a considerable percentage of the total traffic volume. Abdullah has investigated the gross vehicles weights of approximately one hundred thousand vehicles in a period of four months. He found that the overloaded vehicles formed $24 \%$ to $29 \%$ of the total vehicles under his investigations (Abdullah, 2011). Osama et. al. have also published several studies investigated the axle overloading of heavy vehicles for a period of one year (Yassenn, Hafez, Endut, Baharom, \& Wahab, 2011; Yassenn, Hafez, Endut, Baharom, \& Wahab, 2012). Through these studies, it was found that, overloaded axles forms $9 \%$ to $12 \%$ of the total number of weighted axles. what even make this problem worse, are the several requests made by Malaysian logistic sector asking the government to allow increase of heavy vehicles weight limits (Li, 2009; The Star, 2010).

There are several factors accelerating pavement deterioration such as loading, environment, design consideration, and material. However, the most important factor causing the most deterioration is the traffic loading especially the one of the heavy vehicles (Salama, Chatti, \& Lyles, 2006). (Gillespie, 1993) also reported that loading is one the major factors that could cause the pavement damage to increase by a factor of twenty. Research carried out in US and South Africa reported that overloading causes pavement damages to increase out of the proportion, and that an axle loaded double the legal limits may cause the pavement damage to increase between four and sixty times as much damage as the legally loaded axle (CSIR, 1997).

Rutting damage ratios are used to represent the rutting damage caused by a certain loading with a certain axle configuration in terms of the damage caused by single standard axle load (8.16 tons). Multiplying the rutting damage ratio with the traffic volume of a certain a vehicle will give an equivalent number of standard axle load that will give the same rutting damage. However, if this factors are underestimated due to overloading, the 
pavement will encounter premature failures and this causes high maintenance cost. On the other hand, if this damage ratio is overestimated, this will cause unnecessary expenditures in over-designing.

The main objective of this paper is to use actual traffic data and weight of heavy vehicles to develop rutting damage ratios for each heavy vehicle type, for the flexible pavements and overlay design at the northern part of Malaysian peninsula.

This paper is organized as follows: Section 2 describes the detailed methodology used in this study. Section 3 introduces the results obtained by finite element analysis and Weight-In-Motion stations, this section is divided into five sub-sections based on study locations. Finally, section 4 presents our conclusions.

\section{Methodology}

This section describes the methodology followed in this study to achieve its objectives (Figure 1). Data were collected using Weight-In-Motion (WIM) devices, Falling Weight Deflectometer (FWD), Ground Penetration Radar (GPR), Coring and Dynamic Cone Penetration (DCP) Testing. Using the previous devices and testing, four types of data was collected namely: heavy vehicles traffic volume, heavy vehicles weights, pavements layers' strength (Elasticity Moduli), and pavement layers' thicknesses. The previous data were then used in finite element analysis to determine the maximum compressive strains based on actual pavements' properties and heavy vehicles' properties. After that, the maximum compressive strains were used to determine the rutting damage ratios as shown later in this chapter.

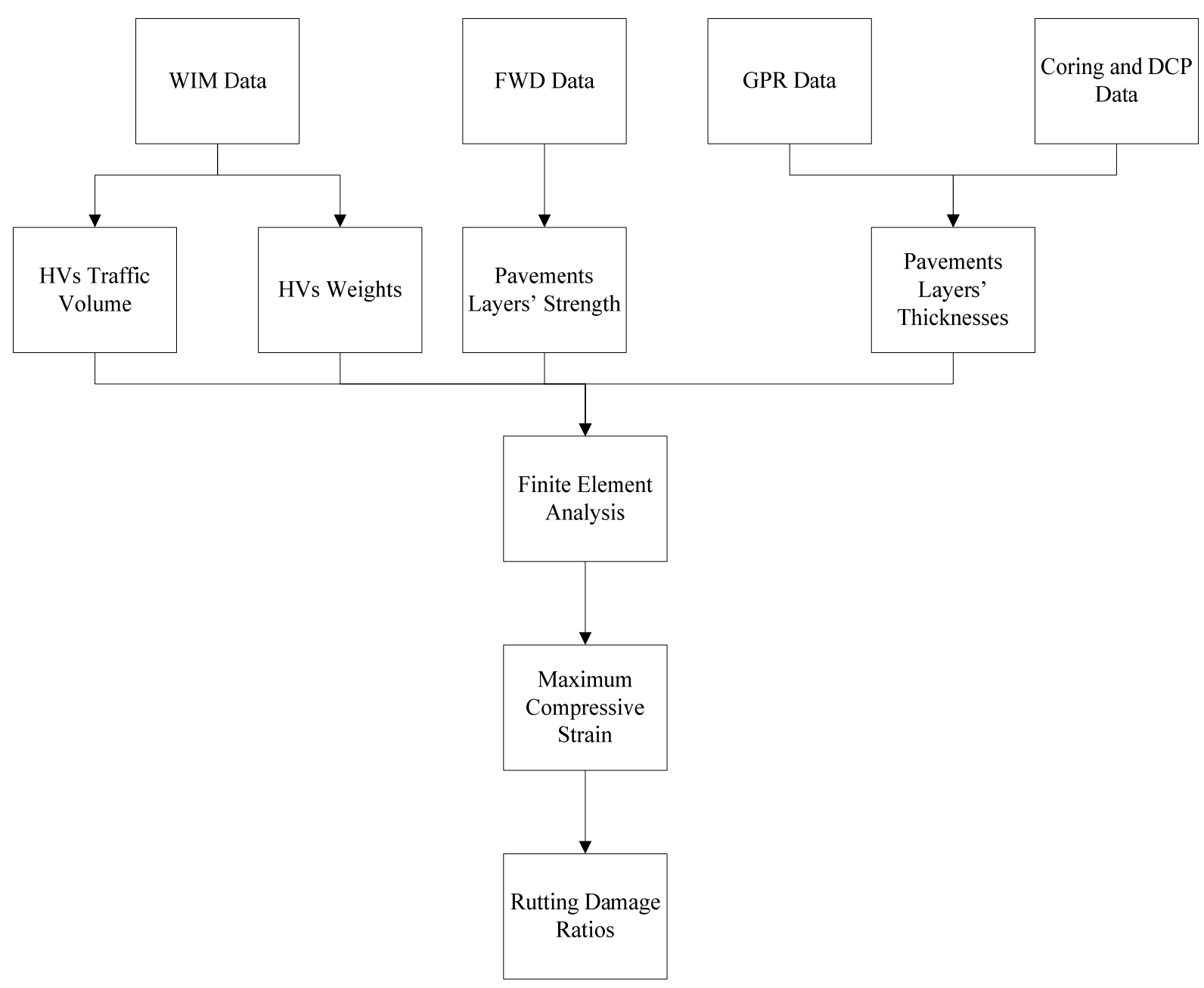

Figure 1. Study Methodology 
The heavy vehicles traffic volume and weights were collected by PLUS expressway Berhad from several weighting stations spread along the longest Malaysian expressway (North-South-Expressway). For the purpose of this study, the data collected by five weighting stations spread along the northern part of Malaysian peninsula.

The counting of heavy vehicles traffic volume and weighting was carried out using weight-in-motion systems. . The weight-in-motion systems are very reliable and accurate systems installed on the pavement of the selected sites. This weighting systems are capable of determining the heavy vehicles gross vehicle weight and axles loading at normal traffic speed without the need of these vehicles to stop.

There are many advantages of the Weight-In-Motion system. One of these advantages is the high processing rate it can weigh the vehicles at normal speed which allows it to process a large number of vehicles comparing to the static weighting system. Another advantage is the ability of the system to have a continuous data processing rather than sampling technique which is used in the static weighting system, which eliminates any bias in the collected data. One more advantage is that since this system reduces the accumulation of the heavy vehicles leading to the weigh station, the weighting process is safer. A further advantage is that the Weight-In-Motion system can weigh the vehicle without alerting the driver, which results in a more truthful data since the drivers will not try to avoid the weighting process.

Although there are many advantages for using the Weight-In-Motion system, there are also some disadvantages. The fact that trucks do not stop at the weighting station reduces the number of different types of data collected in the normal static weighting station. These data include fuel type, origin, destination, and loaded or unloaded status. However, as these data are not required in the study objective, this makes the weight-in-motion system a very good choice for this study (Figure 2).
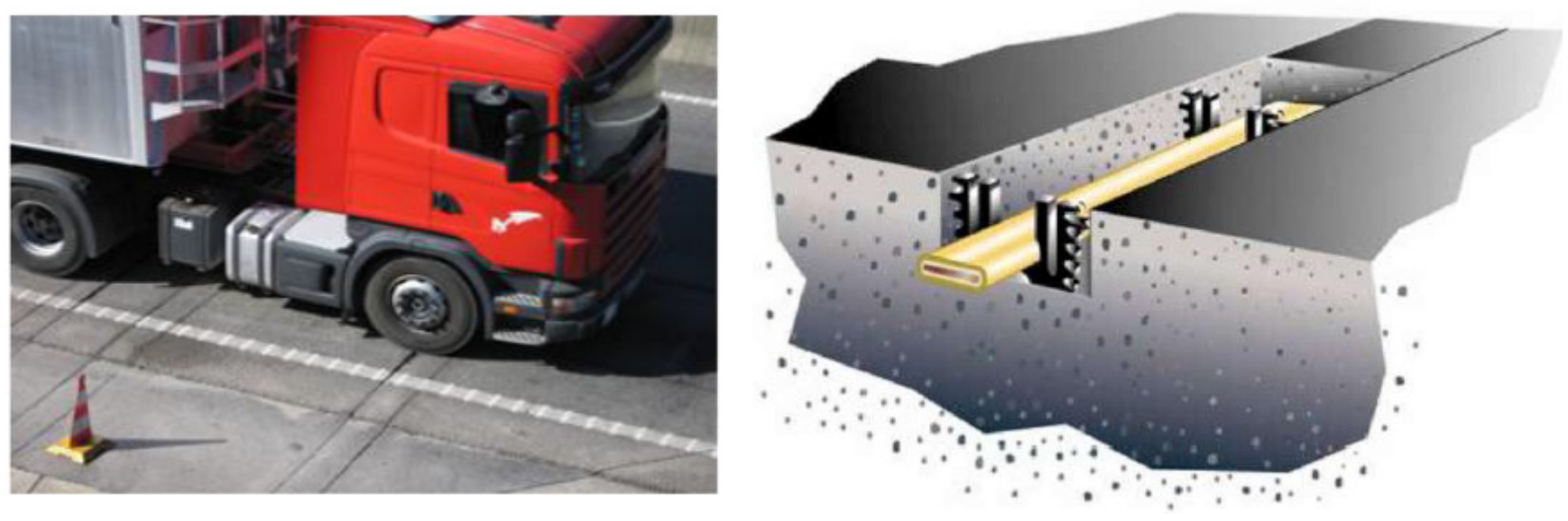

Figure 2. Weight-In-Motion System (IRD, 2012)

In this study, the data collected by the Weight-In-Motion stations were used to determine the traffic volumes and vehicles weights for each heavy vehicles types. Although, the data were collected along the Main Expressway in the area, it is logical to believe that the heavy vehicles weights in the rest of the road network wouldn't be much different, since the same trucks which use the main expressway require also to use the rest of the road network to reach their potential destinations.

In this study, data collected from the following weight-in-motion stations (Figure 3) were used:

1. Alor Setar

2. Gurun

3. Bertam

4. Bukit Merah

5. Taiping

Using pilot study, ten types of heavy vehicles were found to be forming the extreme majority of heavy vehicles operating in Malaysian road network. These vehicles types were used in this study and they are as follow:

a) Single unit trucks with two axles (SU 2)

b) Single unit trucks with three axles (SU 3) 
c) Single unit trucks with four axles (SU 4)

d) Single trailer trucks with four axles (ST 4)

e) Single trailer trucks with five axles (ST 5)

f) Single trailer trucks with six axles (ST 6)

g) Multi trailer trucks with five axles (MT 5)

h) Multi trailer trucks with six axles (MT 6)

i) Multi trailer trucks with seven axles (MT 7)

j) Busses (B)

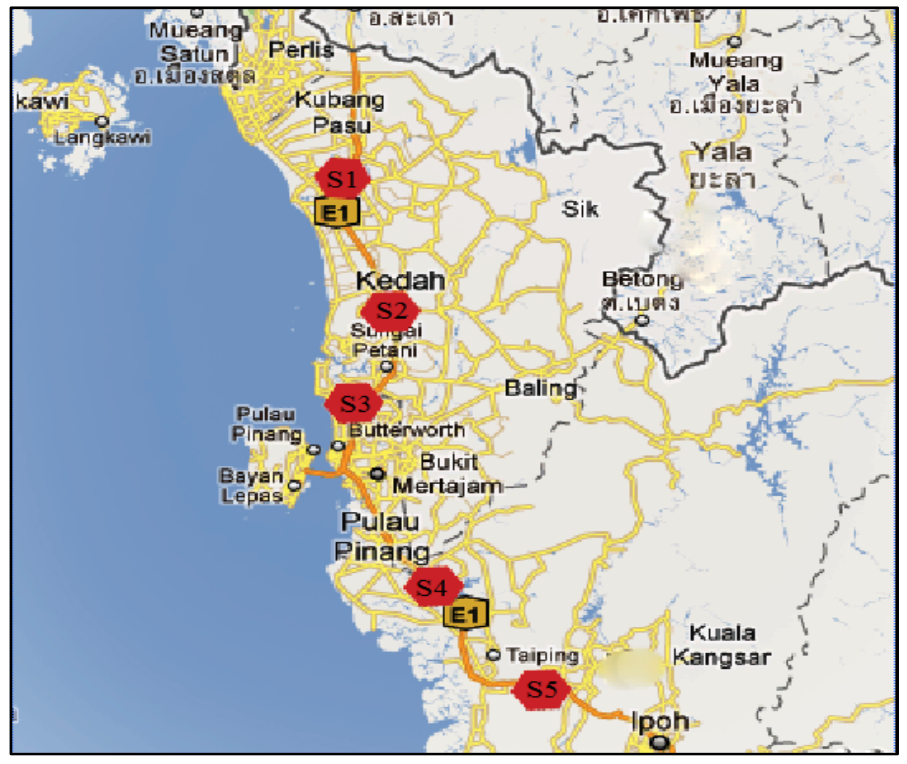

Figure 3. Weight-In-Motion Approximate Locations. S1At Alor Setar, S2 At Gurun, S3 At Bertam, S4 At Bukit Merah, And S5 At Taiping

After collecting the traffic volume and weight data, flexible pavement of the North-South Expressway was analysed using finite element analysis (Figure 4) to estimate the rutting life of the pavement under the current loading, and to compare it with its rutting life under standard axle loading. To perform this analysis, it is necessary to identify pavement layer thicknesses and elasticity moduli. These two types of data were collected by PLUS Expressway Berhad every 250 meters. The data were collected using Falling Weight Deflectometer (FWD), Ground Penetration Radar (GPR), Coring and Dynamic Cone Penetration (DCP). 


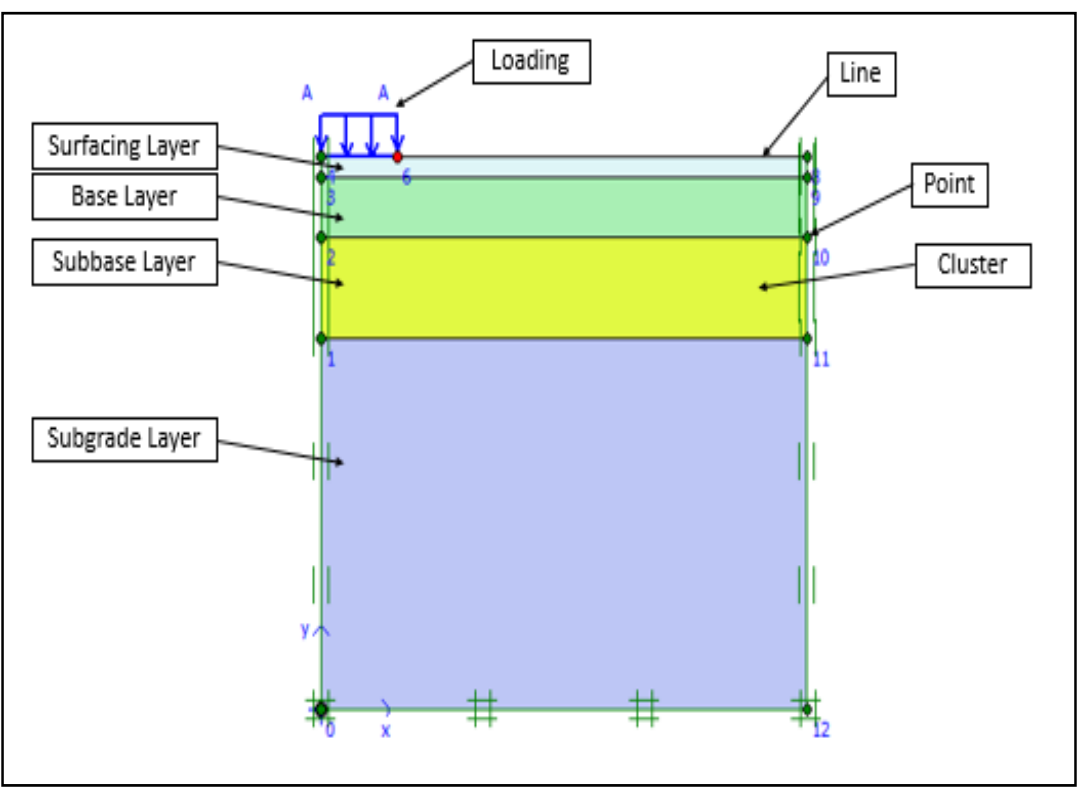

A: Single Axle with Single Tire

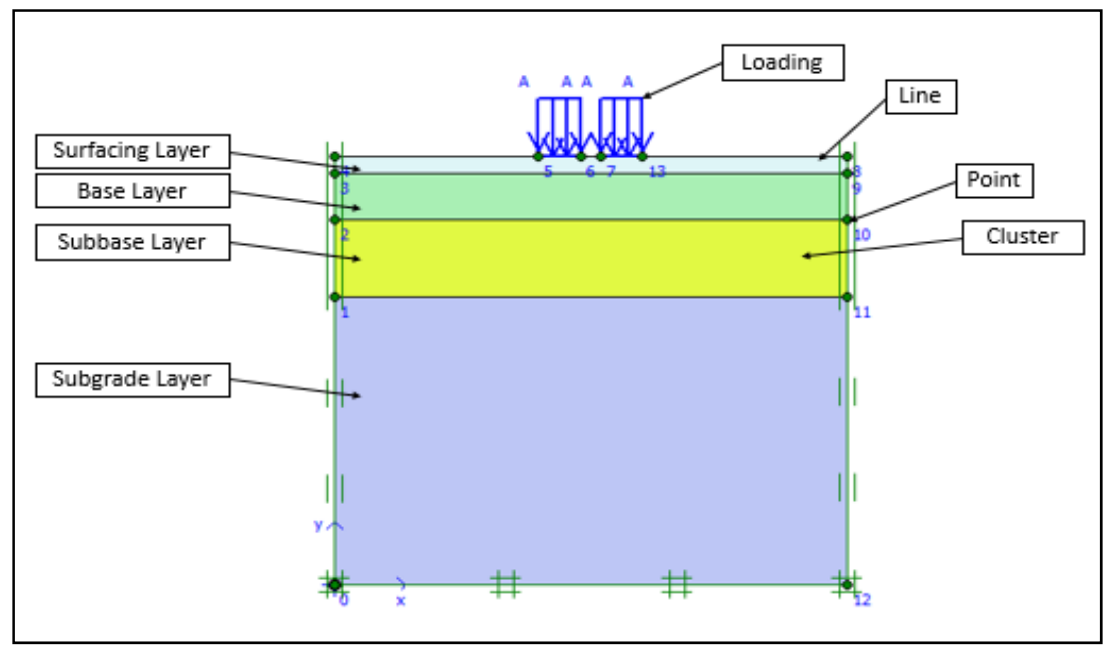

B: Single Axle with Two Tires

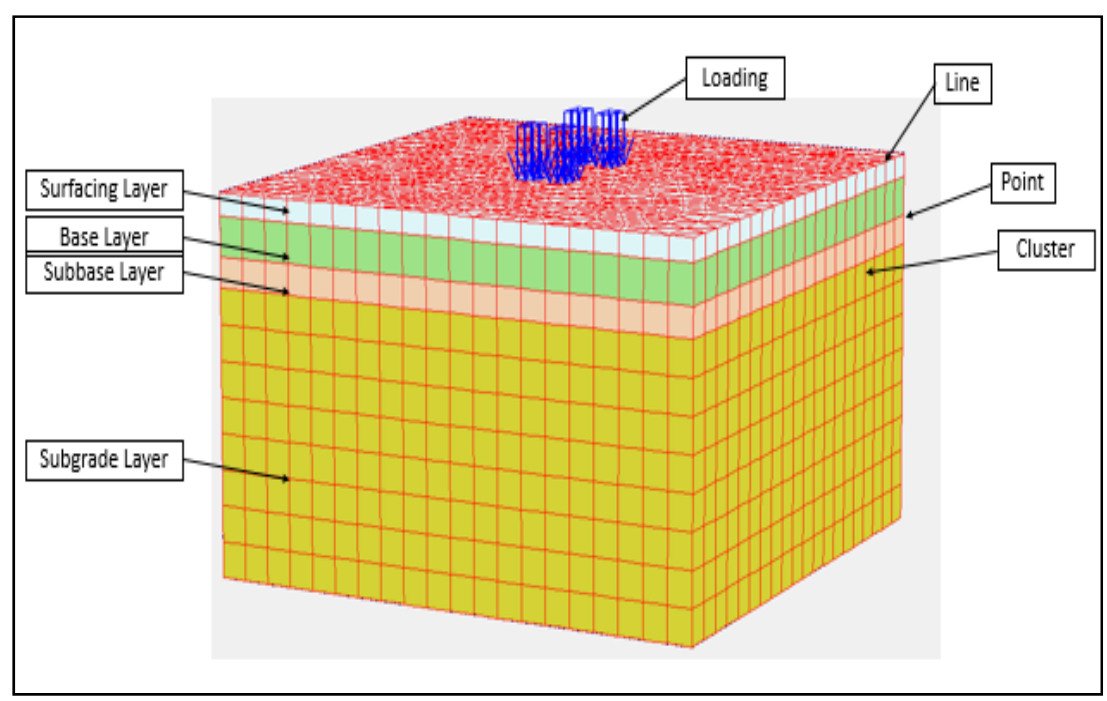

C: Tandem Axle 


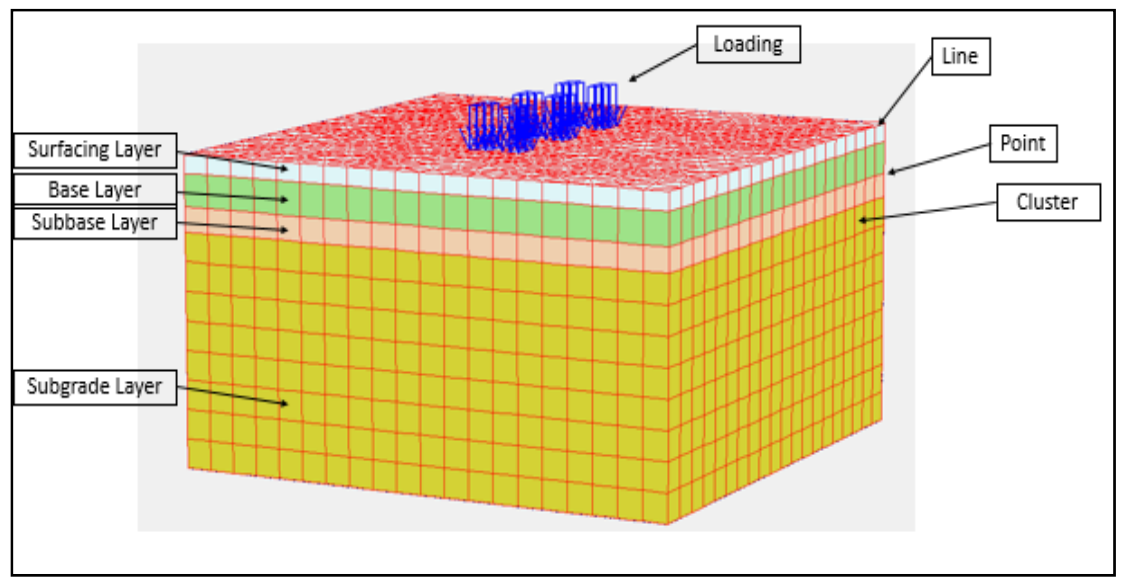

D: Tri-Axle

Figure 4. Finite Element Geometry Used for Pavement Analysis Based on Axle Type

The pavement cross-sections were analysed to determine the maximum compressive strain at the top of each subgrade layer. The compressive strains were used to determine the pavement rutting life as shown by the following formula:

Where:

$$
N_{R}=f_{4}\left(\varepsilon_{c}\right)^{-f_{5}}
$$

$N_{f}$ : Allowable number of load repetition before rutting failure.

$\varepsilon_{t}:$ Maximum compressive strain at the top of subgrade

$f_{4}, f_{5}$ : Constants equal to $1.365 \times 10^{-9}$ and 4.477 based on American Asphalt Institute (Huang, 2004).

The same analysis was done on pavement cross-sections under standard axle load (8.16 tons). Next, rutting damage ratios were determined by dividing the pavement expected rutting life under a specific heavy vehicle loading by the pavement rutting life under standard axle loading. This was done for more than three hundred and fifty kilometers of the north-south expressway, in which the stations are located. Then, the average rutting damage ratio of each heavy vehicle type under this study was calculated.

\section{Results}

This section shows the results obtained by WIM stations and Finite Element Analysis. It shows the traffic volume results and rutting damage ratios results based on each heavy vehicles' type. This section is sub-divided into five sub-sections, based on the location of each WIM station, i.e. Alor Setar, Gurun, Bertam, Bukit Merah and Taiping.

\subsection{Alor Setar}

Figure 5 shows a comparison between number and percentage of weighted heavy vehicles at Alor Setar Weight-In-Motion Station. A total of 768,447 heavy vehicles were weight at Alor Setar Weight-In-Motion Station. It could be clearly seen that the majority of heavy vehicles traffic volumes (84.2\%) is made of merely three types: single unit trucks with two axles $(20.3 \%)$, single trailer truck with 4 axles $(39.7 \%)$ and buses $(24.2 \%)$.

All types of multi-trailer vehicles forms only $1.1 \%$. The multi-trailers with five axles forms $0.9 \%$ and the multi-trailer with seven axles forms only $0.2 \%$. Also, only 5 multi-trailer truck with six axles passed the weighting station. All other types of heavy vehicles form a $14.6 \%$. 


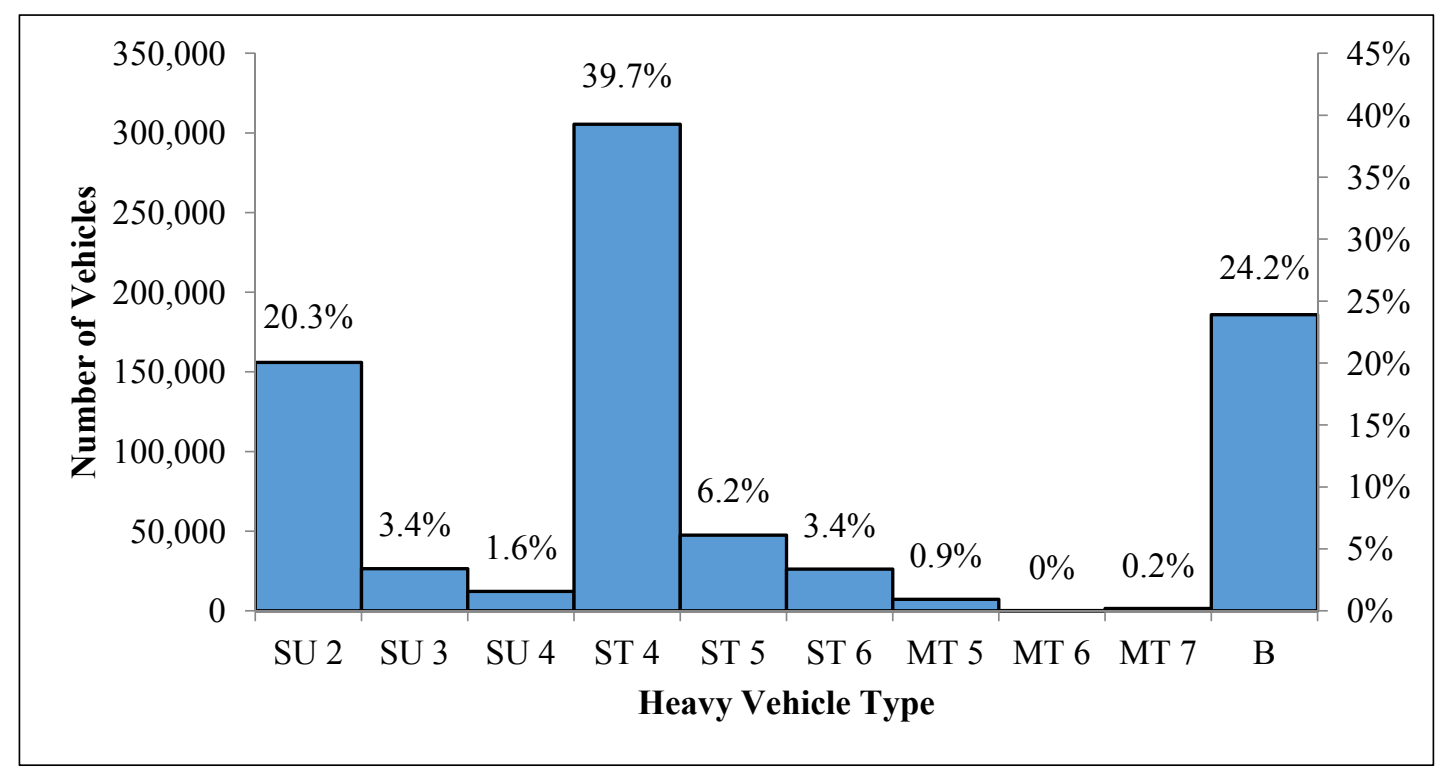

Figure 5. Heavy Vehicles Traffic Volume at Alor Setar Weight-In-Motion Staion

Figure 6 shows a comparison between rutting damage ratio calculated based on average weight for each heavy vehicle category. It can be clearly seen that, the highest rutting damage ratios are caused by multi-trailer vehicles with 6 axles (24.2) and single unit trucks with four axles (19.24). Both of these vehicles causes on average more damage than the damage caused by passing of 19 standard axles weighted 8.16 tons, even though they have four of six axles only. This is caused by overloading. The following highest rutting damage ratios are caused by single trailer trucks with 6 axles and multi-trailer trucks seven axles. Both of these vehicles causes more rutting damage than the rutting caused by passing of 12 standard axles. The rest of the heavy vehicles have a rutting damage ration less than 8 . The lowest rutting damage ratio is caused by the single unit trucks with three axles (3.13), caused by lightly loading this heavy vehicle type.

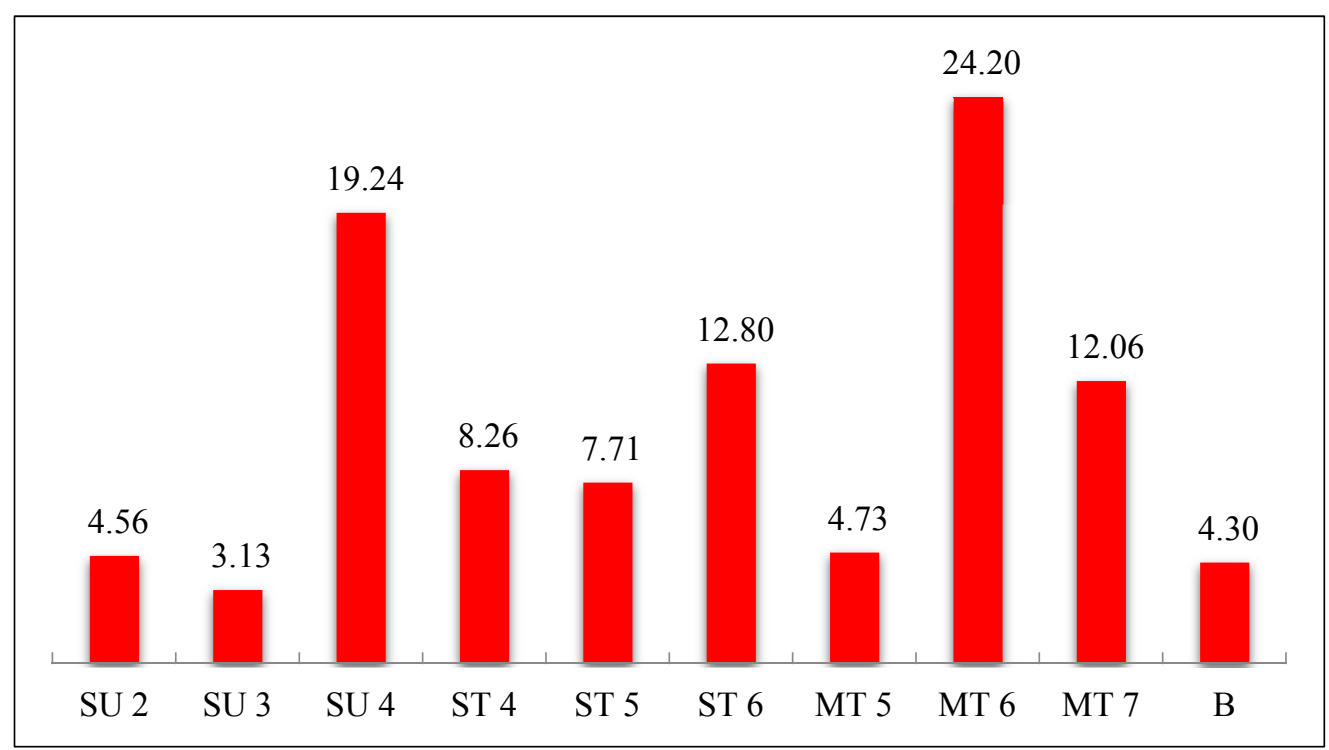

Figure 6. Heavy Vehciles Rutting Damage Ratio at Alor Setar Weight-In-Motion Station

\subsection{Gurun}

Figure 7 shows a comparison between numbers of weighted heavy vehicles at Gurun Weight-In-Motion Station. A total of 961,008heavy vehicles were weight at Gurun Weight-In-Motion Station. It could be clearly seen that 
the majority of heavy vehicles traffic volumes $(85.1 \%)$ is made of merely three types: single unit trucks with two axles (50.7\%), single trailer truck with 4 axles $(19.1 \%)$ and buses $(15.3 \%)$.

All types of multi-trailer vehicles forms only $3 \%$. The multi-trailers with five axles forms $2.9 \%$ and the multi-trailer with six axles forms only $0.1 \%$. Noteworthy that, multi-trailers with seven or more axles didn't pass the weighting station. All other types of heavy vehicles form only $11.9 \%$

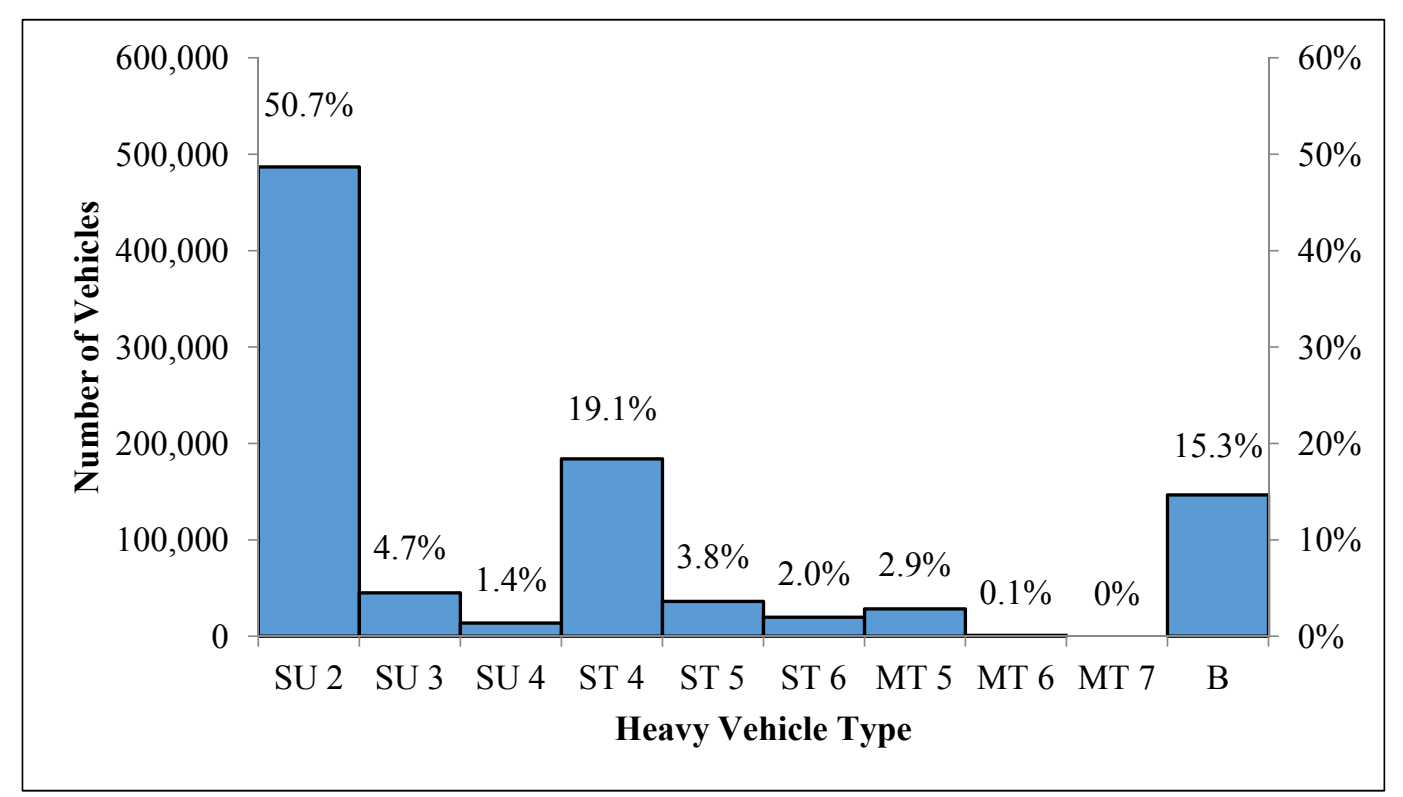

Figure 7. Heavy Vehicles Traffic Volume at Gurun Weight-In-Motion Staion

Figure 8 shows rutting damage ratios calculated for the heavy vehicles passed the Gurun Weight-In-Motion station. It could be easily seen that rutting damage ratios of some vehicles types is very high. The highest rutting damage ratio is caused by multi-trailer trucks with 6 axles, their rutting damage ratio is almost 70, which indicates that this type of trucks causes a rutting damage more than the rutting damage caused by 70 standard axles. This caused by extremely overloading this type of vehicles around this weight-in-motion station. A similar high damage ration was calculated for the multi-trailer trucks with five axles (48.36). The following highest rutting damage ratios are caused by single unit trucks with four axles (29.16) and single trailer trucks with six axles (28.68). On the other hand, the minimum rutting damage ratio is caused by busses (3.34). Worth mentioning that, the rutting damage ratio of multi-trailer trucks with seven axles was not calculated at this station since no multi-trailer trucks with 7 axles or more passed this station. 


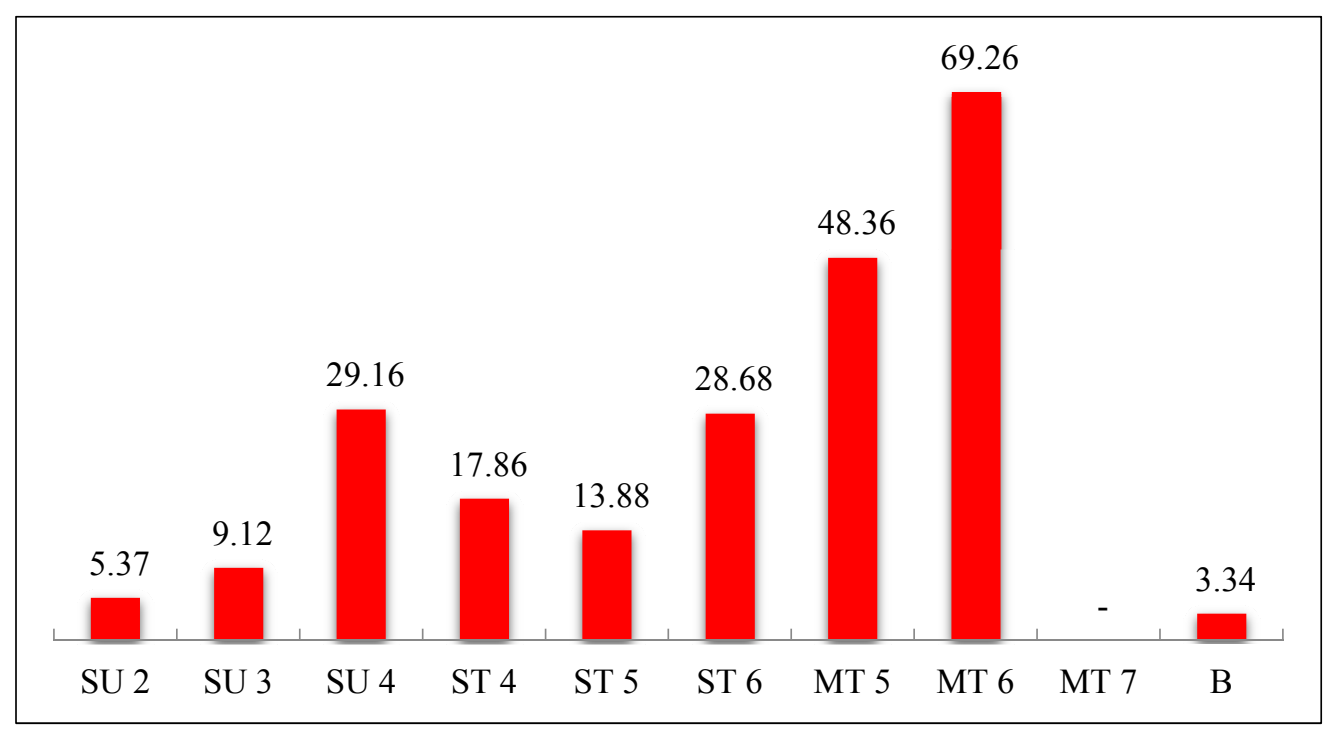

Figure 8. Heavy Vehciles Rutting Damage Ratio at Gurun Weight-In-Motion Station

\subsection{Bertam}

Figure 9 shows a comparison between numbers of weighted heavy vehicles at Bertam Weight-In-Motion Station. A total of $1,347,849$ heavy vehicles were weight at Bertam Weight-In-Motion Station. It could be clearly seen that the majority of heavy vehicles traffic volumes $(84.7 \%)$ is made of merely three types: single unit trucks with two axles $(22.3 \%)$, single trailer truck with 4 axles $(39.3 \%)$ and buses $(23.1 \%)$.

All types of multi-trailer vehicles form only $1.7 \%$. The multi-trailers with five axles form $1.3 \%$ and the multi-trailer with seven axles forms only $0.4 \%$. All other types of heavy vehicles form only $13.6 \%$.

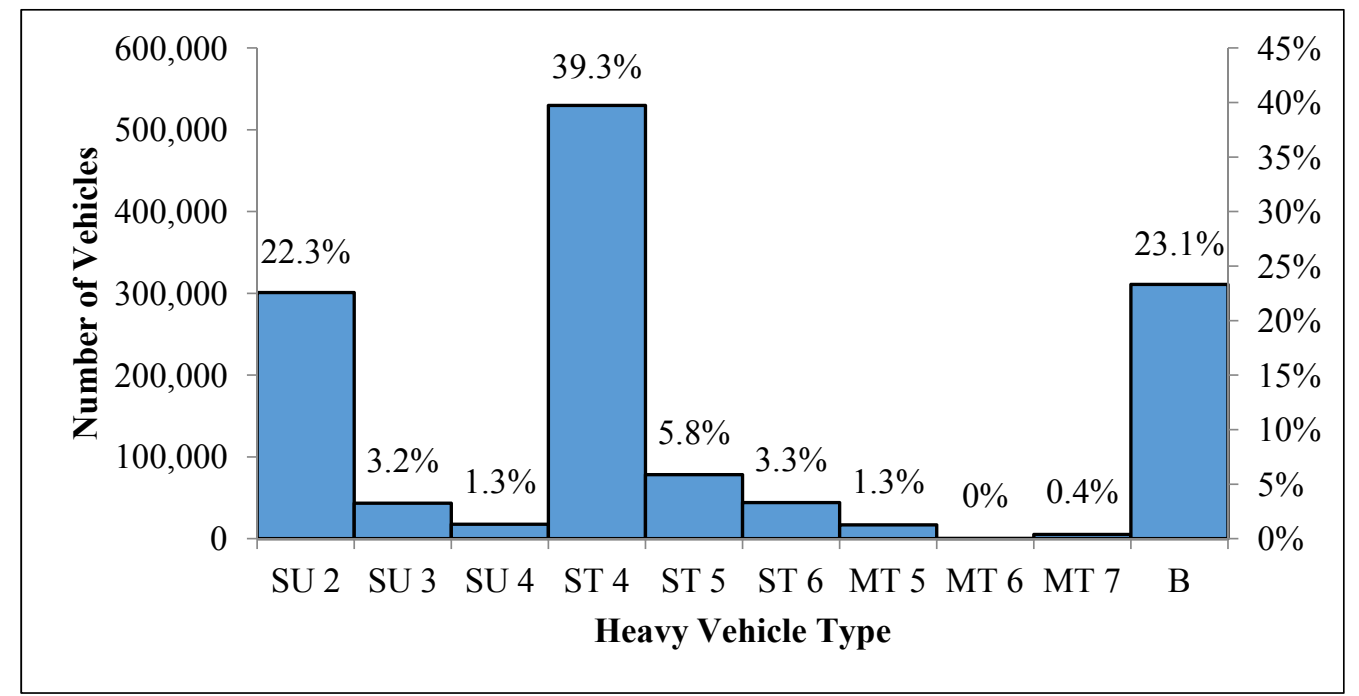

Figure 9. Heavy Vehicles Traffic Volume at Bertam Weight-In-Motion Staion

Figure 10 shows a comparison between rutting damage ratio calculated for each heavy vehicle type at Bertam Wight-In-Motion station. Noticeably, the highest rutting damage ratio is caused by multi-trailer trucks with six axles, their rutting damage ratio is more than 36 . Which indicates that, this type of vehicle causes a rutting damage equivalent the rutting damage caused by passing of approximately 37 standard axles (8.16 tons). This mainly caused due to the high overloading of this vehicle class. The following highest rutting damage is caused by single unit trucks with 4 axles (14.02) and single trailer trucks with 6 axles (13.54). Conversely, the lowest rutting damage ratio is caused by busses (2.60) and single unit trucks with two axles (1.91). 


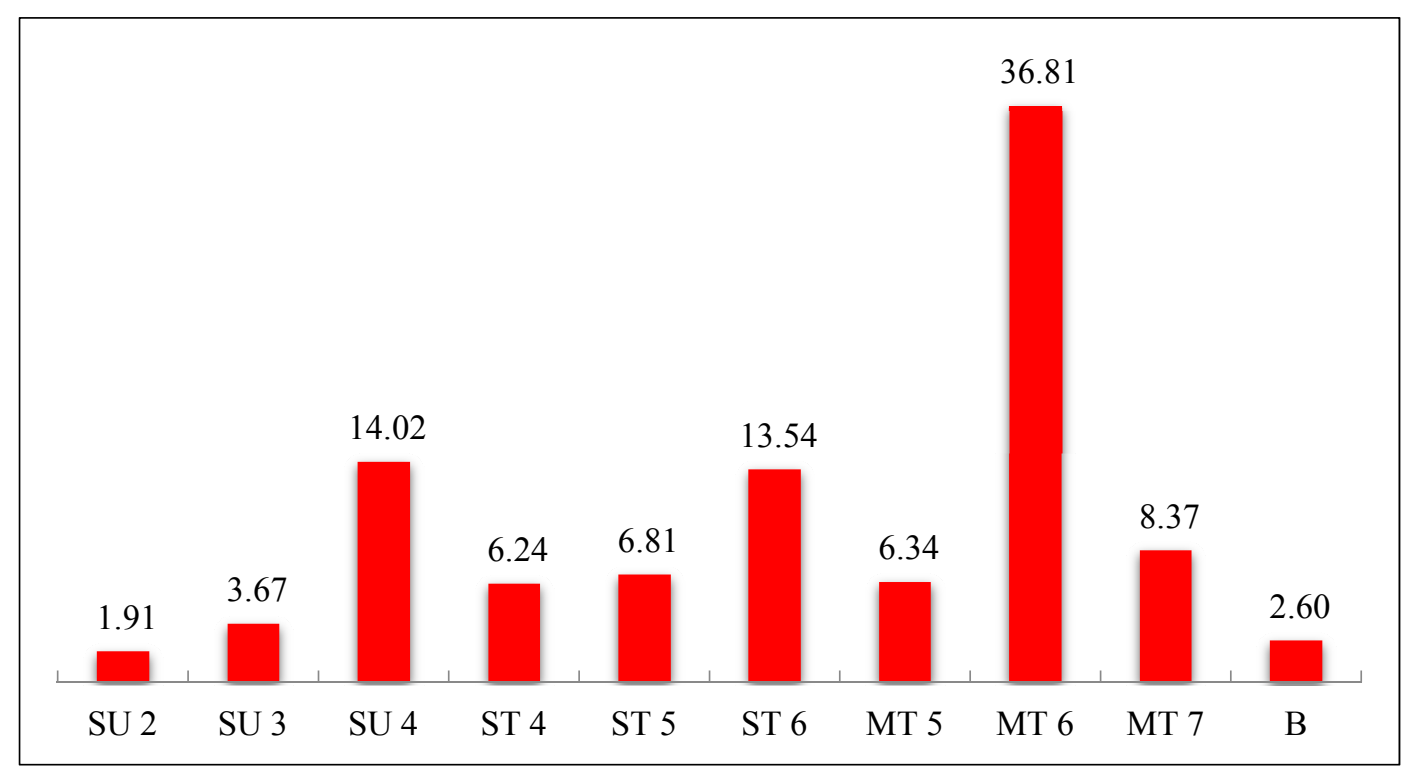

Figure 10. Heavy Vehciles Rutting Damage Ratio at Bertam Weight-In-Motion Station

\subsection{Bukit Merah}

Figure 11 shows a comparison between numbers of weighted heavy vehicles at 2.4. Bukit

Merah

Weight-In-Motion station. A total of 1,577,504 heavy vehicles were weight at Bukit Merah Weight-In-Motion Station. It could be clearly seen that the majority of heavy vehicles traffic volumes $(85.4 \%)$ is made of merely three types: single unit trucks with two axles $(27.7 \%)$, single trailer truck with 4 axles $(32.8 \%)$ and buses $(24.9 \%)$.

All types of multi-trailer vehicles form only $3.4 \%$, which is solely made by multi-trailer trucks with five axles. All other types of heavy vehicles form only $11.2 \%$.

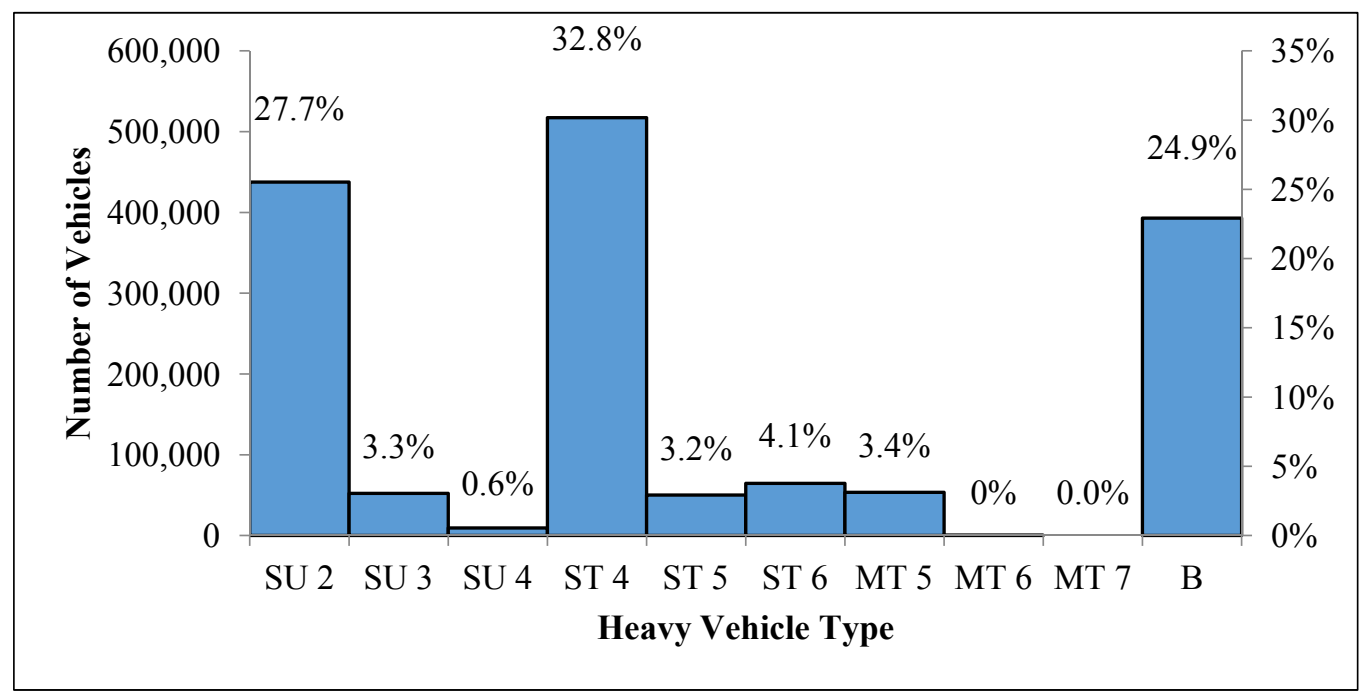

Figure 11. Heavy Vehicles Traffic Volume at Bukit Merah Weight-In-Motion Staion

Figure 12 shows the rutting damage ratio for each heavy vehicle class calculated at Bukit Merah Weight-In-Motion Station. It can be clearly seen that several vehicles causes more than 20 times damage than the one caused by the standard axle load. The highest rutting damage ratio is owned by multi-trailer trucks with 6 axles, they caused a rutting damage ratio of more than 51 this high rutting damage ratio is caused by axle extremely overloading of this vehicle type. The following highest rutting damage ratios are caused by single trailer trucks (34.15 to 21.00). On the other hand, the lowest rutting damage ratio is caused by single unit trucks 
(5.31). Noteworthy, the rutting damage ratio of multi-trailer tracks with seven axles were not calculated at this weighting station, due to the absence of this vehicle type at this station.

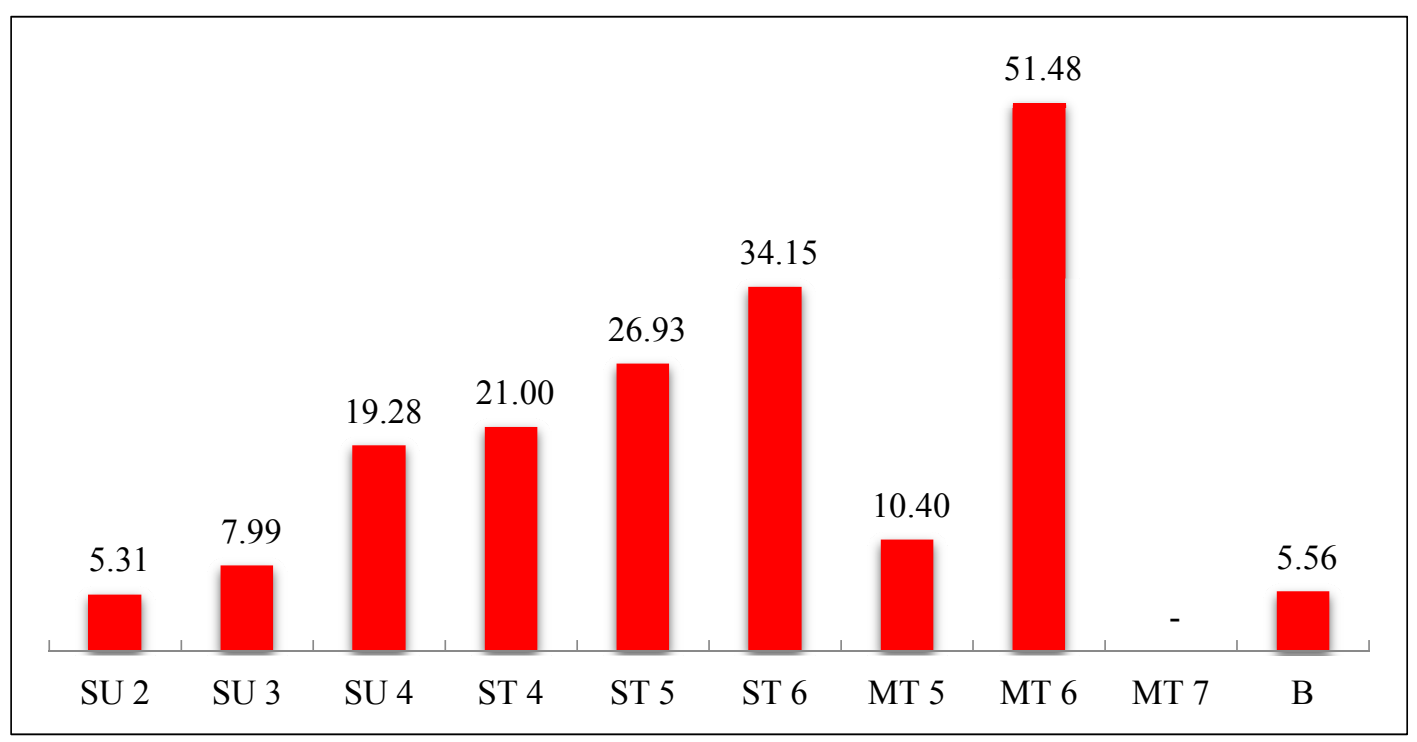

Figure 12. Heavy Vehciles Rutting Damage Ratio at Bukit Merah Weight-In-Motion Station

\subsection{Taiping}

Figure 13 shows a comparison between numbers of weighted heavy vehicles at Taiping Weight-In-Motion Station. A total of $1,000,265$ heavy vehicles were weight at Taiping Weight-In-Motion Station. It could be clearly seen that the majority of heavy vehicles traffic volumes $(85.3 \%)$ is made of merely three types: single unit trucks with two axles (24.0\%), single trailer truck with 4 axles $(29.1 \%)$ and buses $(32.2 \%)$.

All types of multi-trailer vehicles forms only $1.8 \%$. The multi-trailers with five axles forms $1.2 \%$ and the multi-trailer with seven axles forms only $0.6 \%$. Besides, only 32 multi-trailer truck with six axles passed the weighting station. All other types of heavy vehicles form $12.9 \%$.

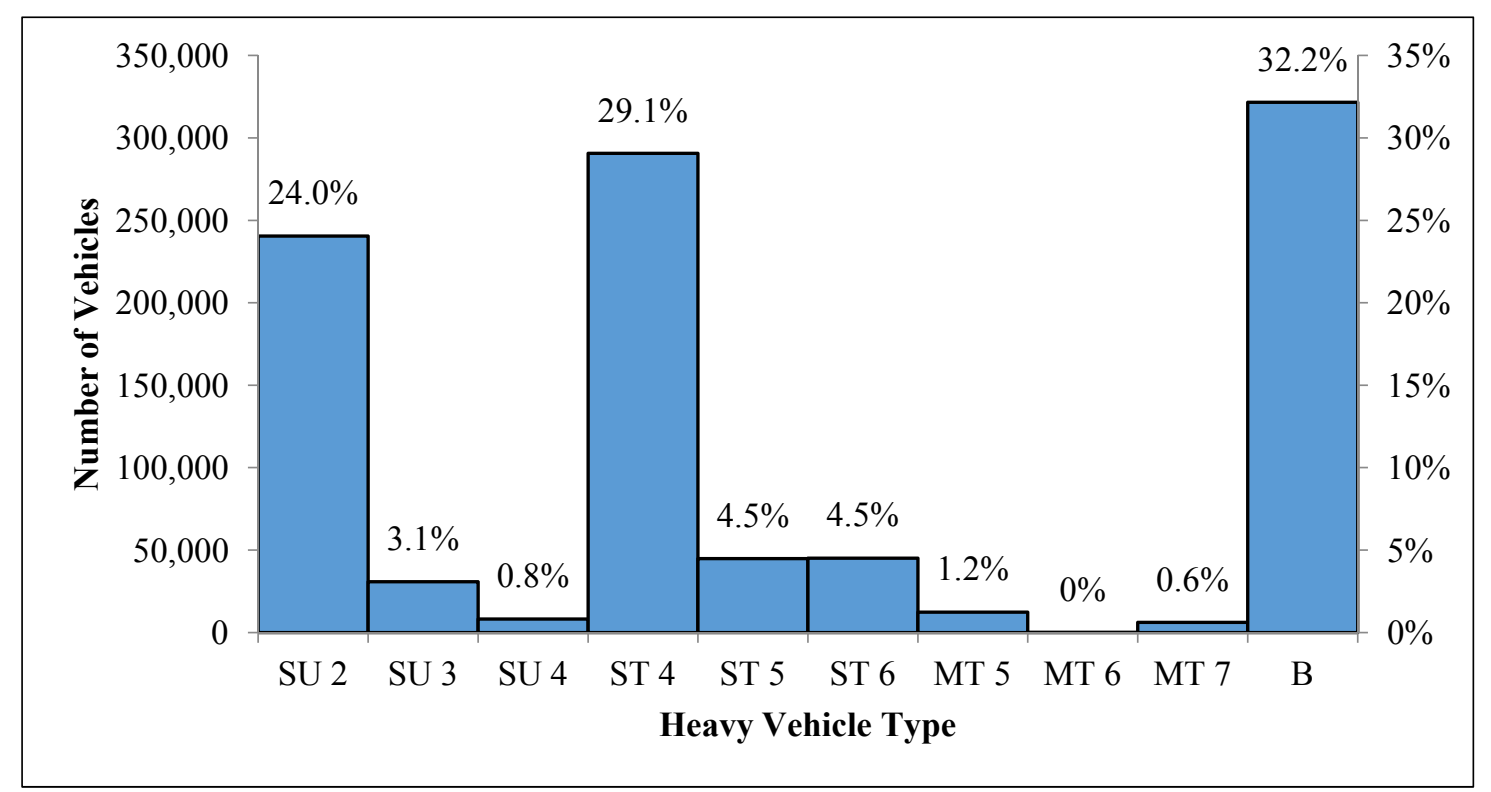

Figure 13. Heavy Vehicles Traffic Volume at Taiping Weight-In-Motion Staion 
Figure 14 shows the damage ratios based on rutting criteria calculated for each heavy vehicle type at the last weighting station (Taiping). Not similar to the previous stations, the rutting damage ratio at this weighting station is not as high as the rest of the weighting station. The overall gross vehicles weight of each heavy vehicle classes are lesser than the gross vehicle weights at the other stations. This is maybe caused by the higher weight enforcement at this station. However, it also can be seen that the muti-trailers with seven and six axles has the highest rutting damage ratios 8.67 and 8.56 respectively. On the other hand the minimum rutting damage ratios are caused by single unit tucks with two axles (2.51) and Busses (2.9).

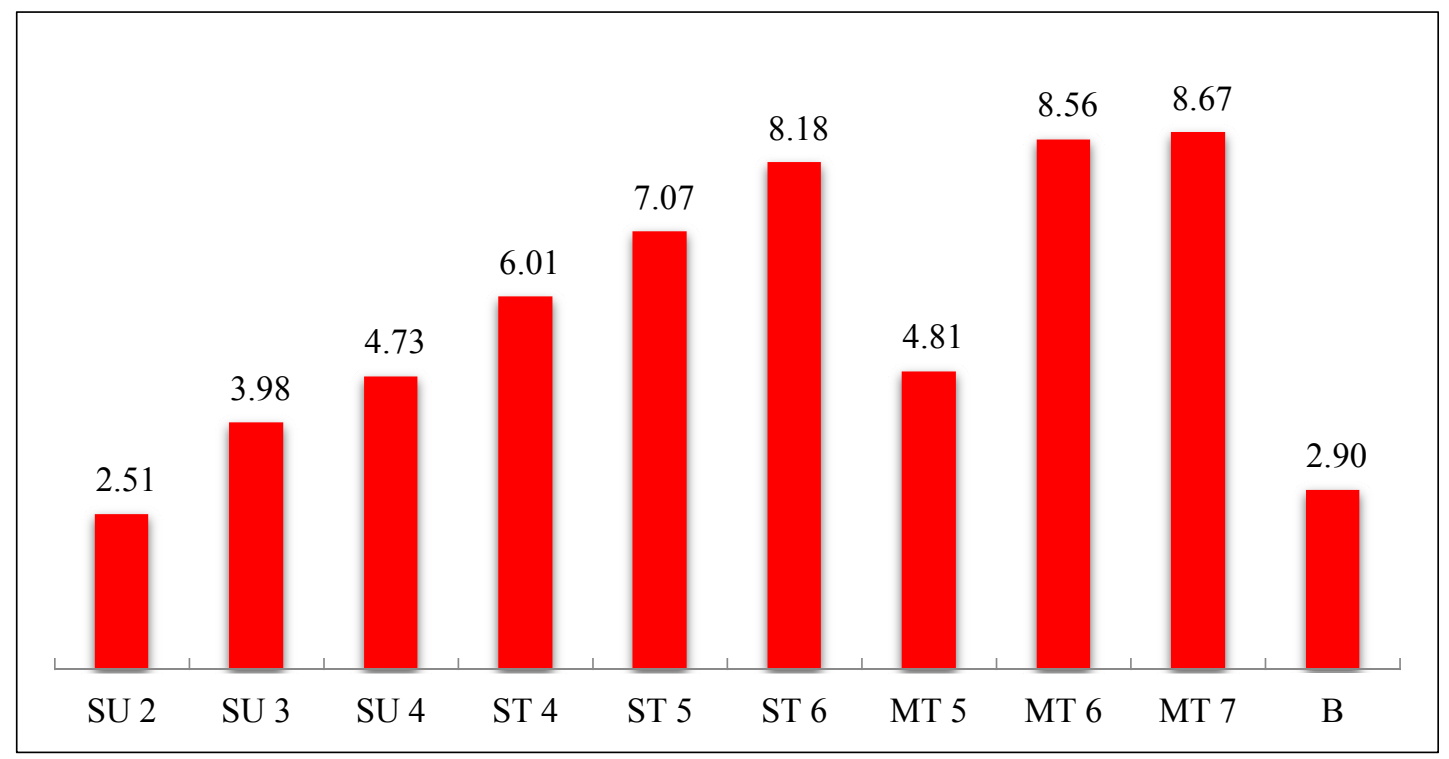

Figure 14. Heavy Vehciles Rutting Damage Ratio at Taiping Weight-In-Motion Station

\section{Conclusion}

Based on the analysis of the traffic volume and weight of approximately five million and two hundred thousand heavy vehicles collected by five weight-in-motion stations, and the analysis of more than $350 \mathrm{~km}$ of flexible pavements, the following conclusions could be made.

The majority of heavy vehicles moving in the northern part of Malaysian Peninsula are: Single unit trucks with two axles (18\% to $51 \%)$, Single trailer trucks with four axles (19\% to $48 \%)$, and Buses $(15 \%$ to $32 \%)$. These three types of vehicles forms more than $80 \%$ of the heavy vehicles traffic. All multi-trailer trucks form a very small percentage $(<3 \%)$, especially the one with six or seven axles. They approximately equal to $0 \%$ of the total heavy traffic volume. All the remaining types of heavy vehicles forms $<20 \%$ of the total heavy traffic volume.

Based on the calculation of rutting damage ratios, it was concluded that the multi-trailer trucks have the highest rutting damage ratios (up to $\approx 70$ ). Comparing with multi-trailer trucks, single trailer trucks and single unit trucks with four axles which has a medium rutting damage ratios (up to $\approx 35$ ). Single unit trucks with two and three axles, and busses have the lowest rutting damage ratios $(<10)$.

For the purpose of designing new flexible pavements and overlay design at the northern part of Malaysian peninsula. The following rutting damage ratios were obtained based on the average weight of each heavy vehicles type: Single unit truck with two axles (4.21), Single unit truck with three axles (6.02), Single unit truck with four axles (18.02), Single unit trailer with four axles (11.89), Single unit trailer with five axles (11.94), Single unit trailer with six axles (20.39), Multi-trailer truck with five axles (17.98), Multi-trailer truck with six axles (63.91), Multi-trailer truck with seven axles (8.94), Busses (3.84).

In case of the absence of detail traffic volume, an average rutting damage ratio was developed for all types of heavy vehicles based on their weight and volume (8.05) can be used. This equivalency factor is higher than what has been suggest by JKR (Malaysian work department) manual of 5, which was based on empirical approach. This might give an explanation for the presence of several premature rutting damages along the roads in Malaysia. 


\section{Acknowledgements}

The writers would like to express their gratitude to PLUS Expressway Bhd. and Soil Central lab Snd. Bhd. for providing Weight-In-Motion and FWD data.

\section{References}

Abdullah, A. S. (2011). Development of Integrated Weigh-in-motion System and Analysis of Traffic Flow Characteristics considering Vehicle Weight. The University of Tokushima Japan.

CSIR Roads and Transport Technology. (1997). The Damaging Effects of Overloaded Heavy Vehicles on Roads (Pad27 - revised). Republic of South Africa.

Gillespie, T. D., Karamihas, S. D., Sayers, M. W., Nasim, M. A., Hansen, W., \& Ehsan, N. (1993). NCHRP Report 353, Effects of Heavy-Vehicle Characteristics on Pavement Response and Performance. Washington, DC: National Cooperative Highway Research Program.

Huang, Y. H. (2004). Pavement analysis and design. United States of America: Pearson/Prentice Hall.

International Road Dynamics Inc. Weigh-in-Motion (WIM). Retrieved August 5, 2012, from http://www.irdinc.com/systems/wim/index.php

Li, K. S. (2009, February 23). Local hauliers want axle-load limits increased to 30pc, Business Times, p. 1. Retrieved from http://findarticles.com/p/news-articles/new-straits-times/mi_8016/is_20090223/local-hauliers-axle-load-limi ts/ai_n44432462/

Raise lorry load limit for all, urges association. (2010, August 18). the star, p. 13.

Salama, H. K., Chatti, K., \& Lyles, R. W. (2006). Effect of Heavy Multiple Axle Trucks on Flexible Pavement Damage Using In-Service Pavement Performance Data. Journal of Transportation Engineering, 132(10), 763-770. http://dx.doi.org/10.1061/(ASCE)0733-947X(2006)132:10(763)

Yassenn, O. M., Hafez, M. A., Endut, I. R., Baharom, B., \& Wahab, M. Y. (2011). Overloading At The Northern Part Of The Malaysian Expressway. Paper presented at the 2011 IEEE Colloquium on Humanities, Science and Engineering Research, Penang, Malaysia. http://dx.doi.org/10.1109/CHUSER.2011.6163839

Yassenn, O. M., Hafez, M. A., Endut, I. R., Baharom, B., \& Wahab, M. Y. (2012). Axle Load Distribution and Overloading at the Central Part of the North-South Expressway in Malaysia. European Journal Of Scientific Research, 79(2).

Yassenn, O. M., Hafez, M. A., Endut, I. R., Baharom, B., \& Wahab, M. Y. (2012). Axle Overloading At The Southern Part Of The North-South Expressway In Malaysia. Paper presented at the 2012 IEEE business engineering and industrial applications colloquium, Malaysia. http://dx.doi.org/10.1109/BEIAC.2012.6226083

\section{Copyrights}

Copyright for this article is retained by the author(s), with first publication rights granted to the journal.

This is an open-access article distributed under the terms and conditions of the Creative Commons Attribution license (http://creativecommons.org/licenses/by/3.0/). 